

\section{Relações entre a estética maneirista e a poética de Walter Salles ${ }^{1}$}

\author{
Relations between mannerist \\ aesthetics and Walter Salles's \\ poetics
}

\section{Resumo}

Este artigo investiga as relações entre a estética maneirista e a poética do cineasta Walter Salles. Para tanto, apresentaremos os pressupostos teóricos que sustentam essa aproximação e, em seguida, realizaremos uma análise do discurso de entrevistas do diretor. Situaremos a obra de Salles na proposta de Gilles Deleuze do terceiro estado da imagem - trata-se de uma nova tipologia para o cinema no contexto da sociedade de controle. Propomos estudar o maneirismo como um gesto estético que tem origem nas artes plásticas e é adotado por cineastas de diversas épocas a partir da perspectiva da sobrevivência das imagens de Aby Warburg, via leitura de Didi-Huberman (2013).

\section{Palavras-chave}

Walter Salles; maneirismo cinematográfico; poéticas do cinema.

\section{Abstract}

This article investigates the relationship between Mannerist aesthetics and the poetics of filmmaker Walter Salles. To do so, we will present the theoretical assumptions that support this approximation, and then we will make an analysis of the director's discourse extracted from interviews. We will situate the work of Salles in the proposal of Gilles Deleuze of the third state of the image, it is a new typology for the cinema in the context of the control society. We propose to study Mannerism as an aesthetic gesture that originates in the plastic arts, and is adopted by filmmakers of different epochs, from the perspective of the survival of the images of Aby Warburg, via DidiHuberman's reading (2013).

\section{Keywords}

Walter Salles; cinematographic mannerism; poetics of cinema. 
O diretor e produtor audiovisual Walter Salles faz parte da renovação do ambiente cultural brasileiro pós-redemocratização. Apesar de ser conhecido principalmente por sua atuação como cineasta, pela qual alcançou repercussão internacional, sua trajetória de mais de 30 anos no audiovisual teve início na televisão. Realizou programas e documentários, sendo um dos pioneiros nas produtoras de vídeo independentes que surgiram nos anos 1980. Sua contribuição artística mais relevante encontra-se, contudo, no cinema.

Central do Brasil (1998) foi o filme que o projetou no cenário brasileiro. $\mathrm{O}$ longa é um dos marcos da Retomada, nos anos 1990, quando a produção cinematográfica volta a ser realizada no país depois de um período de estagnação do setor devido à extinção dos mecanismos estatais de fomento. $\mathrm{O}$ tratamento estetizado dado a um tema de grande prestígio em nossa cinematografia, a dicotomia cidade e campo, gerou um debate estético polarizado, cujos valores ainda permanecem em análises fílmicas atuais.

A inovação de Salles estava em propor uma reflexão do processo modernizador brasileiro, especialmente suas consequências contemporâneas, utilizando uma estética internacional. Ele não foi o único nessa empreitada naquele momento. Lírio Ferreira e Paulo Caldas já tinham apresentado sua abordagem multicultural e pop do sertão em Baile Perfumado (1997). Anos depois, Fernando Meirelles e Kátia Lund lançam Cidade de Deus (2002) que utiliza a estética publicitária na representação da favela. O termo generalista "cosmética da fome", utilizado pela pesquisadora Ivana Bentes para explicar essas novas estéticas, se populariza entre a crítica e a academia. Propaga-se, então, uma visão homogeneizante e pejorativa de propostas formais muito díspares.
A singularidade de Walter Salles na produção brasileira não se deve apenas a Central do Brasil. Ela está na coerência e complexidade estética de sua obra como um todo, que, até o momento, é composta por dez longas-metragens, sendo três deles codirigidos por Daniela Thomas. É especificamente este aspecto que buscamos elucidar, por meio de uma aproximação de seus filmes da estética maneirista.

Partimos da visão de contemporaneidade de Giorgio Agamben (2009) para pensar a poética de Salles. Para o filósofo:

Pertence verdadeiramente ao seu tempo, é verdadeiramente contemporâneo, aquele que não coincide perfeitamente com este, nem está adequado a suas pretensões e é, portanto, nesse sentido, inatual; mas, exatamente por isso, exatamente através desse deslocamento e desse anacronismo, ele é capaz, mais do que os outros, de perceber e apreender seu tempo (...). A contemporaneidade, portanto, é uma singular relação com o próprio tempo, que adere a este e, ao mesmo tempo, dele toma distâncias; mais precisamente, essa é a relação com o tempo que a este adere através de uma dissociação e um anacronismo (Agamben, 2009, p. 58-59, grifo nosso).

Essa forma de encarar o contemporâneo se faz ver na obra do cineasta de diversas maneiras. Neste artigo colocaremos em evidência o aspecto metalinguístico da poética do diretor que, sendo preponderante em sua autoria, será nomeado pela teoria de cinema de estética maneirista. $O$ maneirismo envolve um diálogo com formas estéticas do passado por meio, por exemplo, de citação a cenas de filmes que são objeto de culto de determinado cineasta. Este procedimento de citação reatualiza momentos do passado cinematográfico, coloca em relação diferentes tempos, estéticas, "rechama, re-evoca e revitaliza aquilo que tinha até mesmo declarado morto" (Agamben, 2009, p. 69).

\section{Terceiro estado da imagem}

A proposta de análise que realizaremos da poética de Walter Salles está embasada no modo de ver a imagem contemporânea de Gilles Deleuze em Carta $a$ Serge Daney: otimismo, pessimismo e viagem, texto de 1986 (Deleuze, 2013). Deleuze relaciona as três funções da imagem cinematográfica definidas por Daney em $A$ Rampa (2007), a seus conceitos de "imagem-movimento" e "imagem-tempo". Se a imagem-movimento pode ser expressa na questão "o que há para ver por trás da imagem?" e a imagem-tempo em "o que há para ver na imagem?", o teórico aponta para a insuficiência desses conceitos para lidar com os filmes que surgiam nos anos 1970 e 1980. Ele defende, em diálogo com Daney, a existência de um terceiro estado da imagem, nomeado "maneirismo".

[...] quando não há mais nada para ver por trás dela, quando não há mais muita coisa para ver nela ou dentro dela, mas quando a sempre imagem desliza sobre uma imagem preexistente, pressuposta quando 'o fundo da imagem é sempre já uma imagem', indefinidamente, e que é isto que é preciso ver. [...] a tela não é mais uma porta-janela (por trás da qual...), nem um quadro-plano (no qual...), mas uma mesa de informação sobre a qual as imagens deslizam como 'dados' (Deleuze, 2013, p. 101-102, grifo nosso). 
Esse tipo de cinema, em que "nada mais acontece aos humanos, é com a imagem que tudo acontece" (Deleuze, 2013, p. 102), se vincularia não mais a um pensamento triunfante e coletivo, "mas a um pensamento arriscado, singular, que só se apreende e se conserva no seu 'impoder', tal como ele retorna dos mortos e enfrenta a nulidade da produção geral" (Deleuze, 2013, p. 95).

Ler o cinema de Walter Salles à luz do terceiro estágio da imagem nos parece esclarecedor, assim como vincular sua poética ao maneirismo. Porém, diferentemente de Deleuze e Daney, propomos o maneirismo como uma postura estética, uma opção formal, adotada por alguns cineastas, a fim de não transformar o conceito em uma categoria totalizadora que abarque o cinema contemporâneo em geral.

Além disso, para evitar a tendência de compreender a história do cinema ou da arte como uma sucessão teleológica de períodos, escolas, estilos ou movimentos - clássico/moderno/pós-moderno; cinema da transparência vs. da opacidade - optamos pela postura metodológica do historiador da arte alemão Aby Warburg, via leitura de Didi-Huberman (2013).

Esse olhar para a história da arte baseia-se na sobrevivência das imagens, um pensamento transversal aos recortes cronológicos, anacrônico, que postula a existência de formas que, mesmo passíveis de genealogia, emergem de tempos em tempos, incitadas por certas configurações de contexto - institucional, social e político. Trata-se de uma teoria da complexidade simbólica que concebe a história das formas estéticas como um jogo de pausas, crises, saltos e retornos periódicos de estratégias formais - uma história de gestos que se repetem.
Desta forma, entendemos maneirismo como um gesto estético que tem origem nas artes plásticas, e é incorporado ao cinema, e não como o ressurgimento de um estilo artístico "do passado" no cinema contemporâneo. Essa forma estética é objeto de ressignificações variadas realizadas por cineastas em diferentes épocas e pode-se observar sua permanência na obra de diretores que produzem atualmente.

O termo gesto estético pode ser compreendido como a poética de um cineasta, ou seja, o elemento principal de sua autoria. Foram os críticos da Cahiers du Cinéma dos anos 1950, geração que posteriormente partiu para a realização cinematográfica, formando a Nouvelle Vague, os responsáveis por reivindicar aos cineastas o estatuto de autores por meio da "política dos autores". Essa concepção, que influenciou a reflexão teórica da área, era uma maneira de "associar de um modo irreversível a adesão a um cineasta e a compreensão de seu universo formal, pessoal; para dizê-lo em poucas palavras: sua visão de mundo" (Baecque, 2005, p. 20).

Para esses fundadores da "política dos autores", um cineasta expressa sua visão do mundo pela mise-en-scène, em outras palavras, pela estética dos filmes, da sua realização. Portanto, a moral de um filme, seu conteúdo, sua mensagem, estão intimamente relacionados à forma cinematográfica empregada pelo autor (enquadramentos, movimentos de câmera, montagem, etc). Atenua-se, deste modo, na apreciação fílmica, o peso excessivo conferido aos temas e os juízos de valor em relação aos gêneros cinematográficos empregados em prol de uma análise formal. Já que "o que define um grande filme, o que impõe um grande tema, o que faz com que chegue uma mensagem, é a verdade de sua mise-en-scène" (Baecque, 2005, p. 21).

\section{Gesto maneirista e seus}

procedimentos formais

Se é de caráter duvidoso afirmar que a realização cinematográfica pode ter sido, em algum momento, inocente, sem dúvida, na contemporaneidade, é impensável conceber qualquer exercício de encenação que não leve em conta seu lugar na história das formas. Os cineastas são, em sua maioria, profissionais com sólida formação intelectual, oriundos das universidades. Os públicos, por sua vez, são cada vez mais cinéfilos. Eeles têm à disposição na internet um banco de dados audiovisual que supera, em diversidade, qualquer cinemateca. Com seu centenário, o cinema apresenta uma linguagem e circuito estruturados - com seus gêneros, técnicas, parque exibidor e festivais; ao mesmo tempo em que busca espaço e a reinvenção de suas formas na relação com seus pares audiovisuais - a televisão e o vídeo.

Nesse contexto, a centralidade do procedimento da metalinguagem foi uma das vias encontradas por alguns diretores ao redor do mundo para repotencializar e reafirmar o lugar do cinema. A releitura e reelaboração de aspectos de sua história serviram como ponto de partida para uma ampla revisão crítica da obra de cineastas e linhas estéticas.

Entre as correntes do cinema contemporâneo que privilegiam a metalinguagem, há o maneirismo, um estilo artístico meta-histórico, que surge nas artes visuais. O termo maneirismo designa um estilo da pintura na segunda metade do século XVI, que se apresenta nas obras de Pontormo, Rosso, Parmigianino, entre outros. Esses artistas acentuavam os traços de Michelangelo e Rafael como uma forma de resposta possível, assim como o academicismo e o barroco, ao fim de um ciclo na história da arte, o Renascimento, em que um certo 
ideal de perfeição havia sido atingido. Na estética maneirista, a forma prima sobre o conteúdo; é uma arte do arabesco por vezes gratuito, da elegância, mas também das formas complexas, que favorece assimetrias, deformações (Aumont; Marie, 2008, p. 156). A busca do efeito, a distorção das formas e o privilégio do estilo sobre o realismo caracterizam diversos filmes a partir dos anos 1970. Propôs-se, então, uma extensão da noção de maneirismo ao cinema.

Se, recuperando a reflexão de Serge Daney, nos filmes maneiristas, "o fundo da imagem é sempre já uma imagem. Uma imagem de cinema" (2007, p. 233) e é precisamente a natureza dessas articulações formais que deve ser investigada, podemos chegar a algumas conclusões a respeito deste cinema. Dizer que o "fundo" de inúmeros planos do longa de Brian De Palma Trágica Obsessão (Obsession, 1976) - para ficarmos com um exemplo típico de maneirismo no cinema - consiste em imagens de Um Corpo que Cai (Vertigo, 1958), de Alfred Hitchcock, significa mais do que uma mera homenagem ou citação de De Palma a Hitchcock, pois este procedimento autorreferencial à história do cinema não é apenas um dos aspectos do filme, mas sim seu gesto estético principal, aquele que norteará as demais escolhas filmicas - de atores, locações, elaboração do roteiro, fotografia, cenografia, etc.

Além disso, se a mise-en-scène dos filmes maneiristas necessariamente traz uma releitura de uma imagem cinematográfica precedente, pode-se afirmar que todo filme maneirista é metalinguístico, sem que ele precise trazer a realização cinematográfica em sua narrativa. Trata-se de uma metalinguagem de outra ordem, que se realiza no plano formal. Para citar outro

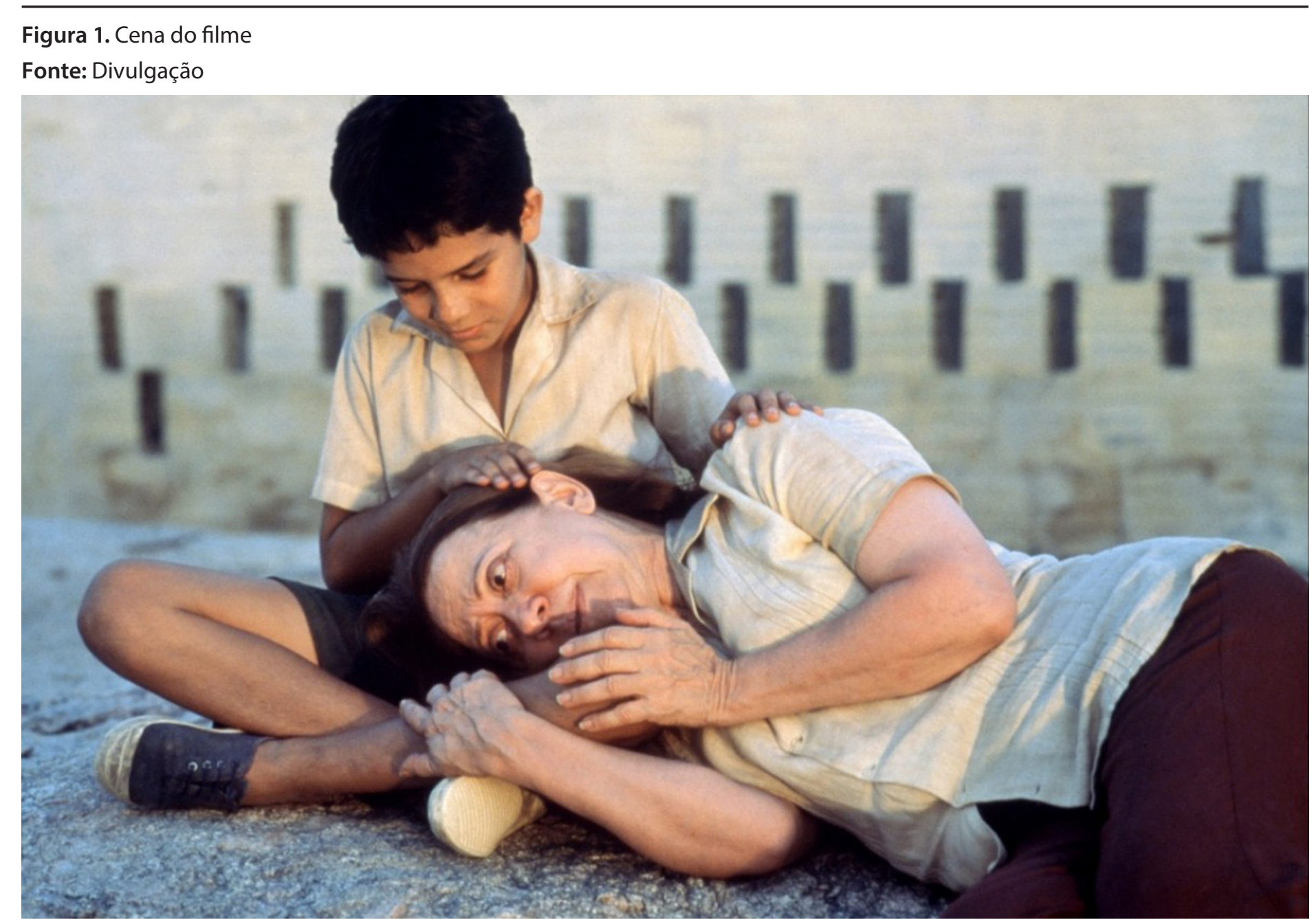

88 PORTO ALEGRE | v. 22 | n. 38 | 2017 | p. 85-93 Sessões do Imaginário

$\mid$ MAGINARIO 
exemplo, desta vez um cineasta maneirista voltado especificamente à releitura de gêneros cinematográficos, John Carpenter, em seu filme Assalto à $13^{a} D P$ (Assault on Precinct 13, 1976). O interesse principal desse longa não está em seu tema - os conflitos vividos em uma delegacia sitiada por uma gangue -, mas se encontra no fato de ser um estudo da migração das demandas simbólicas do western para os gêneros policial e horror, no cinema contemporâneo. Para realizar esta reflexão, Carpenter cria um argumento que atualiza o roteiro do faroeste Onde Começa o Inferno (Rio Bravo, 1959) de Howard Hawks. Por estas configurações formais, pode-se afirmar que Assalto à $13^{a} D P$ é um metafilme.

Uma corrente da produção cinematográfica norte-americana dos anos 1950 foi a primeira a ser lida segundo a perspectiva maneirista. Trata-se da geração de Robert Aldrich e Anthony Mann, entre outros, que retrabalham a mitologia e os gêneros (o western, o noir, o filme de guerra, etc.) da antiga Hollywood com nova sensibilidade e uma maneira pessoal de representar o mundo que expõe seus desconcertos, suas desarmonias e conflitos internos. A questão é menos de contestar os códigos do que de submetê-los aos limites de sua capacidade de significação, repotencializá-los.

Corroborando esta linha de pensamento, o crítico de cinema Alain Bergala (1985) defende a hipótese de que, analogamente ao que ocorrera após o fim do Renascimento, o cinema vivia um "momento maneirista", entendido como uma tendência estética que se torna predominante com o fim do classicismo, a partir dos anos 1960, e se intensifica na virada da década de 1970 para a de 1980, quando o cinema moderno também atinge um ponto de esgotamento.
Os anos 80 terão visto surgir uma nova espécie de produtos cinematográficos, sobretudo do lado das 'novas imagens', que derivariam de um maneirismo de outra natureza, um tipo de maneirismo à revelia. Desejo me referir a esses cineastas para quem o cinema não tem nem mais Mestres nem mais História, mas se apresenta como uma grande reserva confusa de formas, de motivos e de mitos inertes da qual eles podem beber com toda a 'inocência' cultural, ao acaso de suas fantasias ou modas, para sua empresa de reciclagem de 90 anos de imaginário cinematográfico (Bergala, 1985, p. 15).

Este tipo de produção a que o autor se refere contém imagens acossadas, assim como as do cinema contemporâneo em geral, pelo agravamento da crise da representação causada, entre outros fatores, pela hiper-saturação de imagens propiciada pelo desenvolvimento das mídias.

Filmes identificados nessa tendência, como Paris-Texas (Wim Wenders, 1984), Estranhos no Paraíso (Stranger Than Paradise, Jim Jarmusch, 1984), O Elemento do Crime (Forbrydelsens Element, Lars Von Trier, 1984), Boy Meets Girl (Leos Carax, 1984) e L'Enfant Secret (Philippe Garrel, 1979), teriam em comum a consciência de ter chegado tarde demais: assim como a perfeição da forma clássica já tinha sido atingida e superada havia muito tempo, a energia e a criatividade do cinema moderno se tinham igualmente esgotado ao longo dos anos 1970. “'O maneirismo', escreve Patrick Mauriès, 'se situaria (...) à beira, no limite de uma maturidade que teria concretizado todas as suas potências, queimado seus estoques secretos" (Bergala, 1985, p. 12). A forma que resulta dessa constatação, portanto, é uma forma tardia, e, enquanto tal, traz em si o peso da idade avançada do cinema. A "maneira" se constituiria como uma das respostas possíveis a esse esmagador passado próximo.

O maneirismo envolve, portanto, uma ideia de "cri$\mathrm{se}^{\prime \prime}$ - crise de temas, motivos, formas, mas sobretudo crise dessas articulações, dessas ligações antes naturais, agora disfuncionais em alguns casos e hipertrofiados em outros. Das muitas "maneiras" que se apresentam com mais clareza no começo da década de 1980, Oliveira Jr. destaca duas: a sobrecarga e o retraimento. De um lado, a tensão formal, a hipérbole, a distorção, a anamorfose, a arte fambloyante, vertiginosa, a narrativa em torvelinho (Von Trier, De Palma, Raoul Ruiz). Do outro, o formalismo desafetado, a imobilidade, a duração extenuante, a lentidão, o enredo desdramatizado, a narrativa rarefeita (Wenders, Jarmusch) (Oliveira Jr., 2010, p. 72-73).

A ideia que subjaz a aparição de diversas vertentes de um sobre-cinema ou hipercinema, entre os anos 1970 e os 2000, é a de que não há mais mise-en-scène inocente, e todo o exercício de encenação deve ser deliberado, refletido, consciente do seu lugar na história das formas. Este cinema sobre-enquadrado, sobre-dramatizado, sobre-excitado, sobressaturado de citações é demasiadamente consciente de estar muito avançado na sua história (Oliveira Jr., 2010, p. 83).

\section{Traços maneiristas na obra de} Walter Salles

Devido à profusão de citações ao Cinema Novo e ao diálogo com o cinema de Wim Wenders (Nagib, 2006), além de referências a outros cineastas, acreditamos que a obra de Walter Salles abarca diversas características 
desse cinema "em crise", maneirista, inclusive podendo ser colocada na categoria de cinema de sobre-citação. Porém, diferentemente da citação lúdica pós-moderna, a metalinguagem nos filmes de Salles é carregada de melancolia, um índice de sua postura maneirista.

Na ocasião do lançamento de Central do Brasil, em entrevista do diretor (WS) para os críticos Carlos Alberto Mattos (CAM), José Carlos Avellar (JCA) e Ivana Bentes (IB), estas marcas metalinguísticas são explicitadas.

\section{CAM - O que você conhecia do Nordeste?}

WS-Eutinha,evidentemente,umamemóriavisual. .

\section{IB - Deus e o Diabo. .}

WS - Num primeiro momento uma memória visu al que nós todos temos, a herança cinema novista. (Bentes; Mattos; Avellar, 1998, p. 7-40).

Se, como apontamos, nos filmes maneiristas, "o fundo da imagem é sempre já uma imagem. Uma imagem de cinema." (Daney, 2007, p. 233), vejamos como a colocação de José Carlos Avellar é elucidativa a respeito da apropriação da história do cinema brasileiro realizada por Walter Salles.

JCA - É curioso que em nossa conversa estejamos todo o tempo falando de uma geografia real. Sinto o filme um pouco mais ligado a uma geografia cinematográfica. [...] O Sertão aqui é um pouco menos o Sertão mesmo e um pouco mais o Sertão representação cinematográfica do Brasil, é o Nordeste, ou 'Nordestes', como diz o Walter, enquanto imagem expressiva.

90 PORTO ALEGRE | v. 22 | n. 38 | 2017 | p. 85-93 Sessões do Imaginário
WS - Exatamente.

JCA - Na verdade não é entrar no Sertão, mas pegar do Sertão o que existe de imagem dele enquanto expressão cinematográfica. Eu penso no filme como uma viagem ao Cinema Novo, mais do que uma viagem ao Sertão (Bentes; Mattos; Avellar, 1998, p. 7-40).

Em entrevistas posteriores aos prêmios de Urso de Ouro de melhor filme concedido a Central e Urso de Prata de melhor atriz para Fernanda Montenegro, na edição de 1998 do Festival de Berlim, Walter dá pistas de seu pensamento cinematográfico maneirista.

Um filme nunca existe sozinho. Traz consigo a memória viva de toda uma cinematografia. No caso de Central do Brasil, o desejo de dialogar com uma tradição cinematográfica da qual todos nós devemos nos orgulhar é explícito, assim como é implícita a vontade de comunicação com o jovem cinema brasileiro [...]. Os prêmios para o filme são, portanto, para o cinema brasileiro como um todo...(Bentes; Mattos; Avellar, 1998, p. 7-40).

Em outro trecho da entrevista, Salles justifica uma sequência do filme - em que os personagens tiram uma fotografia que é colocada posteriormente em um monóculo, em uma barraca com a imagem de Padre Cícero - utilizando um argumento metalinguístico: trata-se de uma vontade de homenagear o cineasta Wim Wenders.

IV - Aliás pensando na cultura oral do Nordeste, no ter que ditar as cartas. Um registro fotográfico, no monóculo: não é estranho numa região em que os registros são precários?

WS - Eu preciso confessar pra você, a questão do monóculo é uma questão mais wimwendersziana do que nordestina. [...] Os lugares onde a possibilidade da migração é muito presente suscitam a necessidade de fixação pictórica das pessoas que partiram. Se você entra numa casa nordestina, [...] você encontra um número impressionante de retratos e imagens que permitem a lembrança daqueles que partiram. A questão da imagem não é decorativa [...]. Constitui-se numa memória, numa necessidade intrínseca quase que de sobrevivência. Uma forma de resistir é lembrar a pessoa que se foi (Bentes; Mattos; Avellar, 1998, p. 7-40).

Existe uma possibilidade de dupla leitura do trecho acima citado. A explicação que o cineasta realiza da importância da imagem no Nordeste pode ser expandida, tendo em vista o conteúdo de suas demais falas durante a entrevista. Podemos recontextualizar seu discurso na problemática da imagem no período da crise do cinema dos anos 1980, consequência dos impactos do vídeo e da televisão. As diversas inserções na narrativa do filme de índices metalinguísticos, como as citações ao Cinema Novo, a Wenders, além de fotografias, imagens da iconografia cristã, referências à história das artes visuais, quadros e do dispositivo ótico do monóculo, poderiam ser interpretadas como um ato de resistência, de preservação da memória do cinema, de sua história, de seus mestres: "Uma forma de resistir é lembrar a pessoa que se foi". 


\section{Considerações finais}

A aproximação que propomos entre a estética maneirista e a poética do cineasta Walter Salles tem como pressupostos teóricos a contextualização da obra de Salles no terceiro estado da imagem, definido por Deleuze como uma nova tipologia para o cinema na sociedade de controle. Consideramos o maneirismo como um gesto estético que tem origem nas artes plásticas, e é adotado por cineastas de diversas épocas, a partir da perspectiva da sobrevivência das imagens de Aby Warburg, via leitura de Didi-Huberman (2013), que defende uma concepção anacrônica da história da arte como um jogo de pausas, crises, saltos e retornos periódicos de estratégias formais.

Consideramos a metalinguagem o procedimento formal preponderante dos filmes maneiristas, assim como aponta Serge Daney, já que neles, "o fundo da imagem é sempre já uma imagem. Uma imagem de cinema" (2007, p. 233) e é precisamente a natureza dessas articulações formais que deve ser analisada. Este procedimento autorreferencial à história do cinema não é apenas um dos aspectos dos filmes maneiristas, mas sim "seu gesto estético principal", aquele que norteará as demais escolhas fílmicas. Se a mise-en-scène dos filmes maneiristas necessariamente traz uma releitura de uma imagem cinematográfica precedente, pode-se afirmar que todo filme maneirista é metalinguístico, sem que ele precise trazer a realização cinematográfica em sua narrativa. Trata-se de uma metalinguagem que se realiza no plano formal.

Por meio de trechos de entrevistas concedidas por Walter Salles na ocasião do lançamento de Central do
Brasil, buscamos apontar as afinidades entre o discurso reflexivo do realizador sobre o filme e o gesto maneirista. Além disso, ressaltamos que as diversas inserções na narrativa do filme de índices metalinguísticos, como as citações ao Cinema Novo, a Wenders, além de fotografias, imagens da iconografia cristã, referências à história das artes visuais, quadros e do dispositivo ótico do monóculo, poderiam ser interpretadas como um ato de resistência, de preservação da memória do cinema, de sua história, de seus mestres.

\section{Referências}

AGAMBEN, Giorgio. $\mathbf{O}$ que é o contemporâneo? E outros ensaios. Tradutor Vinícius Nicastro Honesko. Chapecó: Argos, 2009.

AUMONT, Jacques; MARIE, Michel. Dicionário teórico e crítico do cinema. Lisboa: Texto \& Grafia, 2008.

BAECQUE, Antoine de (org.). La política de los autores. Buenos Aires: Paidós, 2005.

BENTES, Ivana; MATTOS, Carlos Alberto; AVELLAR, José Carlos. Conversa com Walter Salles: o documental como socorro nobre da ficção. Cinemais. Rio de Janeiro, n. 9, jan./fev. 1998.

BERGALA, Alain. D'une certaine manière. Cahiers du Cinéma. n. 370, abr. 1985

DANEY, Serge. A rampa. São Paulo: Cosac Naify, 2007.

DELEUZE,Gilles.CartaaSergeDaney:otimismo, pessimismo e viagem. In: Conversações. São Paulo: Ed. 34, 2013.
DIDI-HUBERMAN, Georges. A imagem sobrevivente: história da arte e tempo dos fantasmas segundo Aby Warburg. Rio de Janeiro: Contraponto, 2013.

NAGIB, Lúcia. A utopia no cinema brasileiro: matrizes, nostalgia, distopias. São Paulo: Cosac Naify, 2006.

OLIVEIRA JR., Luiz Carlos Gonçalves de. O cinema de fluxo e a mise en scène. 2010. Dissertação (Mestrado em Meios e Processos Audiovisuais) - Escola de Comunicações e Artes da Universidade de São Paulo, USP, São Paulo.

\section{Referências audiovisuais}

CALDAS, Paulo; FERREIRA, Lírio. Baile Perfumado. [Filme-vídeo]. Produção de Paulo Caldas e Lírio Ferreira, direção de Paulo Caldas e Lírio Ferreira. Brasil, 1997. 93 min. color. son.

CARAX, Leos. Boy Meets Girl. [Filme-vídeo]. Produção de Patricia Moraz, direção de Leos Carax. França, 1984. 100 min. color. son.

CARPENTER, John. Assault on Precinct 13. [Filmevídeo]. Produção de J. Stein Kaplan, direção de John Carpenter. Estados Unidos, 1976. 91 min. color. son.

DE PALMA, Brian. Obsession. [Filme-vídeo]. Produção de Harry Blum e George Litto, direção de Alfred Hitchcock. Estados Unidos, 1976. 98 min. color. son.

GARREL, Philippe. L'Enfant Secret. [Filme-vídeo]. Produção de Philippe Garrel, direção de Philippe Garrel. França, 1979. 92 min. P \& B. son. 
HAWKS, Howard. Rio Bravo. [Filme-vídeo]. Produção de Howard Hawks, direção de Howard Hawks. Estados Unidos, 1959. 141 min. color. son.

HITCHCOCK, Alfred. Vertigo. [Filme-vídeo]. Produção e direção de Alfred Hitchcock. Estados Unidos, 1958. 128 min. color. son

JARMUSCH, Jim. DRIVER, Sara. Stranger Than Paradise. [Filme-vídeo]. Produção de Sara Driver, direção de Jim Jarmusch. Alemanha/Estados Unidos, 1984. 89 $\min$. P \& B. son

LUND, Kátia; MEIRELLES, Fernando. RIBEIRO, Andrea Barata. RIBEIRO, Mauricio Andrade. Cidade de Deus. [Filme-vídeo]. Produção de Andrea Barata Ribeiro e Mauricio Andrade Ramos, direção de Fernando Meirelles e Kátia Lund. Brasil, 2002. 130 min. color. son.

SALLES, Walter. Jia Zhangke, um Homem de Fenyang [Vídeo]. Produção e direção de Walter Salles. Brasil/ França, 2014. 105 min. color. Son.

. CLERMONT-TONNERRE, Martine de. REDFORD, Robert. Central do Brasil. [Filme-vídeo]. Produção de Arthur Cohn, Martine de Clermont-Tonnerre, Walter Salles e Robert Redford, direção de Walter Salles. Brasil/ França, 1998. 113 min. color. son.

. COHN, Arthur. Abril Despedaçado. [Filme-vídeo]. Produção de Arthur Cohn. Direção de Walter Salles. Brasil/França/Suíça, 2001. 105 min. color. son.

COPPOLA, Roman. GILLIBERT, Charles. KAR-
MITZ, Nathanaël. YELDHAM, Rebecca. Na Estrada. [Filme-vídeo]. Produção de Roman Coppola, Charles Gillibert, Nathanaël Karmitz e Rebecca Yeldham, direção de Walter Salles. França/Estados Unidos/ Reino Unido/ Brasil/Canadá/ Argentina, 2012. 137 min. color. son.

DAVIDSON, Doug. LEE, Roy. MECHANIC, Bill. Água Negra. [vídeo]. Produção de Doug Davidson, Roy Lee e Bill Mechanic, direção de Walter Salles. Estados Unidos, 2005. 105 min. color. son.

. FLAKSMAN, Alberto. A Grande Arte. [filme-vídeo]. Produção de Alberto Flaksman, direção de Walter Salles. Brasil/ Estados Unidos, 1991. 99 min. color. son.

NOZIK, Michael. TENENBAUM, Edgard. TENKHOFF, Karen. Diários de Motocicleta. [Filme-vídeo]. Produção de Michael Nozik, Edgard Tenenbaum, Karen Tenkhoff, direção de Walter Salles. Argentina/ Estados Unidos/Chile/Peru/Brazil/Reino Unido/Alemanha/França, 2004. 126 min. color. son.

. THOMAS, Daniela. PESSOA, Beth. O Primeiro

Dia. [Filme-vídeo]. Produção de Beth Pessoa, direção de Walter Salles e Daniela Thomas. França/Brasil, 1998. 75 min. color. son.

THOMAS, Daniela. RAMOS, Mauricio Andrade. YELDHAM, Rebecca. Linha de Passe. [Filme-vídeo]. Produção de Walter Salles, Daniela Thomas, Mauricio Andrade Ramos e Rebecca Yeldham, direção de Walter Salles e Daniela Thomas. Brasil, 2008. 113 min. color. son.

THOMAS, Daniela. TELLES, António da Cunha.
TAMBELLINI, Flávio R. Terra Estrangeira. [Filme-vídeo]. Produção de António da Cunha Telles e Flávio R. Tambellini, direção de Walter Salles e Daniela Thomas. Brasil, Portugal, 1995. 110 min. P \& B. son.

VON TRIER, Lars. HOLST, Per. Forbrydelsens Element. [Filme-vídeo]. Produção de Per Holst, direção de Lars Von Trier. Dinamarca, 1984. 104 min. color. son.

WENDERS, Wim. DAUMAN, Anatole. GUEST, Don. Paris-Texas. [Filme-vídeo]. Produção de Anatole Dauman e Don Guest, direção de Wim Wenders. Alemanha/Estados Unidos/França/Reino Unido, 1984. 147 min. color. son

\section{Notas}

1 Versão deste artigo foi apresentada no I Cinemídia - Encontro Internacional do Grupo de Estudos sobre História e Teoria das Mídias Audiovisuais, realizado de 16 a 20 de novembro de 2015 na UFSCar.

2 Doutoranda em Comunicação e Semiótica pela Pontifícia Universidade Católica de São Paulo (2015). Mestre em Comunicação e Semiótica pela Pontifícia Universidade Católica de São Paulo (2013). (Programa de Pós-Graduação em Comunicação e Semiótica - PUCSP: Rua Ministro Godoy, 969, 4\%. andar - Sala 4E-08, CEP 05015-901, Perdizes, São Paulo/SP). E-mail: cyntia. calhado@gmail.com.

3 Jia Zhangke, um homem de Fenyang (2014), Na Estrada (2012), Linha de Passe (2008, codireação de Daniela Thomas), Água Negra (2005), Diários de Motocicleta (2004), Abril Despedaçado (2002), O Primeiro 
Dia (1999, codireção Daniela Thomas), Central do Brasil (1998), Terra Estrangeira (1995, codireção Daniela Thomas) e A Grande Arte (1991).

4 Livro que reúne artigos do crítico publicados na revista Cahiers du Cinéma.

5 Não confundir com a refilmagem homônima do longa de Carpenter realizada em 2005 por Jean-François Richet. 